\title{
STUDY OF THE INHIBITION POTENTIAL OF REMDESIVIR DERIVATIVES ON MPRO OF SARS-COV-2
}

\author{
Aluísio Marques da Fonseca ${ }^{*}{ }^{凶}$ (iD), Antonio Luthierre Gama Cavalcante 2 iD, \\ Rubson Mateus Matos Carvalho 2 iD , Jeferson Falcão do Amaral ${ }^{3}$ iD, Regilany Paulo \\ Colares $^{2}$ iD , Emmanuel Silva Marinho 4 iD, Moises Maia Neto 5 iD \\ ${ }^{*}$ 1 Mestrado Acadêmico em Sociobiodiversidades e Tecnologias Sustentáveis - MASTS, Instituto de \\ Engenharias e Desenvolvimento Sustentável, Universidade da Integração Internacional da \\ Lusofonia Afro-Brasileira, 62785-000, Acarape-CE, Brazil \\ 2 Instituto de Ciências Exatas e da Natureza, Universidade da Integração Internacional da \\ Lusofonia Afro-Brasileira, 62785-000, Acarape-CE, Brazil \\ 3 Instituto de Ciências da Saúde, Universidade da Integração Internacional da Lusofonia Afro- \\ Brasileira, 62785-000, Acarape-CE, Brazil \\ ${ }^{4}$ Faculdade de Filosofia Dom Aureliano Matos - FAFIDAM, Universidade Estadual do Ceará, \\ 62.930-000, Centro, Limoeiro do Norte-CE, Brazil \\ ${ }^{5}$ Curso de graduação em farmácia, Centro Universitário Fametro, 60010-260, Fortaleza-CE, Brazil
}

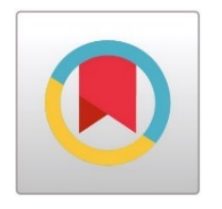

DOI: https://doi.org/10.29121/granthaalayah.v8.i11.2020.2342

Article Type: Research Article

Article Citation: Aluísio Marques da Fonseca, Antonio Luthierre Gama Cavalcante, Rubson Mateus Matos Carvalho, Jeferson Falcão do Amaral, Regilany Paulo Colares, Emmanuel Silva Marinho, and Moises Maia Neto. (2020). STUDY OF THE INHIBITION POTENTIAL OF REMDESIVIR DERIVATIVES ON MPRO OF SARS-COV-2. International Journal of Research GRANTHAALAYAH, 8(11), 164-174. https://doi.org/10.29121/granthaa layah.v8.i11.2020.2342

Received Date: 04 November 2020

Accepted Date: 30 November 2020

Keywords:

Affinity Energy

Ligand

Coronavirus

Sars-Cov-2

\section{ABSTRACT}

The emergence of the new coronavirus (SARS-COV-2) is known to trigger some common diseases in humans such as pneumonia and diarrhea, the search for appropriate therapy combat COVID-19 has been intense and exhaustive.

Motivation/Background: Thus, based on the rational study of drugs, a survey of potential ligands that can inhibit the vital protein in virus replication, the main protease (Mpro), has been carried out worldwide.

Method: In this battle, the antiviral Remdesivir, which was created to fight the Ebola virus, proved, through the molecular anchorage, to be quite effective against its target because it presented affinity energy far superior to its co-crystallized ligand.

Results: In this work, a study was carried out with Remdesivir and its derivatives, obtained in a zinc database 15, to present a possible alternative, based on its structure-affinity, as potential Inhibitors of SARS-COV-2 MPro, with affinity energy ranging from -6.3 to $-8.2 \mathrm{kcal} / \mathrm{mol}$.

Conclusions: It was found that both remdesivir and its diastereoisomeric derivatives have an affinity with the main protease (Mpro), responsible for viral replication, with inhibition capacity and possible alternative in its treatment. 
Aluísio Marques da Fonseca, Antonio Luthierre Gama Cavalcante, Rubson Mateus Matos Carvalho, Jeferson Falcão do Amaral, Regilany Paulo Colares, Emmanuel Silva Marinho, and Moises Maia Neto

\section{INTRODUCTION}

The year 2020 will forever be marked as necessary for public health due to the emergence of the new coronavirus's pandemic, belonging to a family of viruses called Coronaviridae, known to trigger some common diseases in humans such as colds and diarrhea. [1], [2], [3], [4]

Over the past 20 years, Coronavirus has been responsible for two significant pandemics, severe acute respiratory syndrome (SARS)-CoV, 2002, and the Middle East Respiratory Syndrome (MERS)-CoV in 2012. The current epidemic began in the seafood and lived animal market; studies have identified that the etiological agent would be a new coronavirus (SARS-COV-2). [5]

In December 2019, the World Health Organization (WHO) was notified of the pneumonia outbreak in the People's Republic of China, Hubei province, specifically in the city of Wuhan. [6] The first indications of this viral epidemic were reported in this city, where the health system interpreted some of the infected symptoms, diagnosing them with pneumonia. [7], [8], [9]

The symptoms were similar. However, some less common symptoms, such as loss of taste and smell, indicated that the diagnosis was not correct enough. These patients were submitted to several tests and interpreted their daily lives to seek similarities and finalize the diagnosis. [8], [10], [11], [12]

Initially, the new viral disease caused by SARS-COV-2 was called "2019 new Coronavirus" or "2019-nCoV". Subsequently, the terminology was modified by the WHO to COVID-19, where 'CO' means corona, 'VI' for viruses and 'D' for the disease. With the spread and increase in the number of countries that confirmed the cases of COVID-19, on January 30, 2020, the WHO declared this as a Public Health Emergency of International Importance and then, on March 11, 2020, decreed a pandemic of this disease. [5]

Since then, the virus has evolved exponentially and disorderly ly throughout the planet. The most affected continents were Asia, Europe, and the Americas (south and north). [13], [14] Countries like Italy, England, Spain, Germany, and France were among the most affected in Europe due to the large tourist flow. The number of deaths in these countries combined reached more than 150,000, generating an average rate of 1 death per 500 inhabitants. [15], [16] In the U.S. and Brazil, the number of deaths, respectively, stands out. Also, the two countries have about 340,000 deaths. [4], [17], [18], [19]

In this viral pandemic scenario decreed by several countries, many universities and major research centers have turned their efforts into developing combat tools: vaccines, treatment protocols, technology development, and experimental use of new drugs, especially antiviral drugs.

Regarding antivirals, some studies with results available so far have tested the antivirals lopinavir/ ritonavir, remdesivir, and umifenovir. It is emphasized that the remdesivir is still under test in Brazil and still has no registration with ANVISA. Umifenavir also has no registration for use in the country. [20]

Thus, with results still inconclusive, these drugs are allowed to be used only in a context of compassionate use or clinical research duly registered in the country. Their routine use is not indicated for the management of patients with COVID-19. [20]

For the treatment of COVID-19, an ideal antiviral agent should target essential proteins involved in the life cycle of SARS-CoV-2. [21], [22], [23] Currently, the commonly used protocol for treating this disease is the use of HIV protease inhibitors. [24] Several theoretical studies indicate that primary protease (Mpro) provides a highly validated pharmacological target for the discovery and design of inhibitors. [25]

Several researchers have identified potent Mpro inhibitors with the aid of computational techniques and molecular modeling. From molecular dynamics and re-docking, it was possible to confirm its efficiency theoretically. There are reports of potential Inhibitors of SARS-CoV-2 Mpro from derivatives of natural marine products and experimental peptidomimetics $\alpha$-keto amides. Despite the great potential evidenced by the tests, the biochemical behavior in biological systems is often still uncertain due to their toxicity and also because they are not by Lipinski's rule of 5. [26], [27]

Another strategy was the comparison between bioactive compounds and HIV protease inhibitors to evaluate their activity against SARS-CoV-2. Docking and molecular dynamics simulations were performed through an in silico study. According to the researchers, the inhibitors analyzed presented similar results, classifying potentials for the preventive treatment of COVID-19. However, the antiviral Nelfinavir stood out against the others. In addition to Nelfinavir, the combination of inhibitors such as Lopinavir/Ritonavir was considered comparable to those of Nelfinavir, and the others studied. [28] 
Remdesivir, another antiviral, was initially developed to treat Ebola and Marburg virus but has been ineffective for these infections. [29] Currently, it has authorization from the FDA, experimentally for the treatment of COVID-19 in the USA, but only in hospitalized patients in severe condition. The release was made by presenting previous studies that showed its antiviral activity against the classes of viruses that have an RNA, including SARS-CoV-1 because it is an analog of adenosine, which is incorporated into the nascent chains of viral RNA, which can lead to premature interruption of the final chains of this RNA. [30]

In this perspective, computational techniques have enhanced research in this field besides providing the optimization of methods and protocols. Molecular modeling has emerged as an indispensable tool for the beginning of the development of bioactive compounds and biochemical compatibility tests. [31], [32] These computational experiments are performed to achieve the best interaction condition, avoid unnecessary tests, and provide time savings of reagents. [33]

Therefore, molecular simulations have been assisting in developing new drugs for more than 25 years. Molecular modeling is conceptualized as a combination of theoretical and computational techniques for the structural improvement of molecules and to question their behavior. [34], [35] The alignment between molecular modeling and simulation plays an increasingly important role in developing products and processes to overcome various contemporary societal challenges in health, energy, food, water treatment, and environmental protection. [36]

This work aims to study in silico of Remdesivir and its constitutional and diastereoisomeric derivatives to verify its interaction with Mpro protease and be based on new studies, with potential inhibitors for SARS-COV-2 and treatment of COVID-19.

\section{MATERIALS AND METHODS}

Molecular coupling simulations were performed from the screening of 17 structures derived from the antiviral remdesivir in 3D, selected from the ZINC15 repository (https://zinc15.docking.org/substances/home/), [37] Fig. 1., where they were prepared and optimized in the Software Autodock4 tools (1.5.6), [38] as well as the target protein.

The code used was Autodock vina, with its Lamarckian genetic algorithm (AG) in combination with grid-based affinity energy, [39] with the anchor region according to the synthetic binding found co-crystallized in the protein (N3). The main protease protein was obtained from the RCSB Protein Data Bank (PDB ID: 6LU7). [40] Its structure was archived in the Protein Database with a resolution of $2.16 \AA$, determined from x-ray diffraction, classified as viral protein. The rule of 5 Lipinski, [41] RMDS of up to $2.0 \AA$. . [42] and affinity energy greater than $-7.0 \mathrm{kcal} / \mathrm{mol}$ was used as an exclusion factor. The most favorable ones were represented by the lowest free binding energy $(\Delta G)$ [43]. Discovery Studio [44] conducted interaction 3D/2D visualization analysis studies, and Poseview was added. [45], [46]

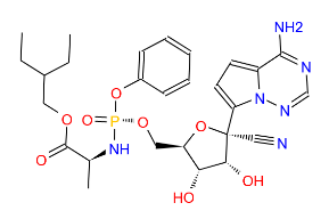

REMDESIVIR

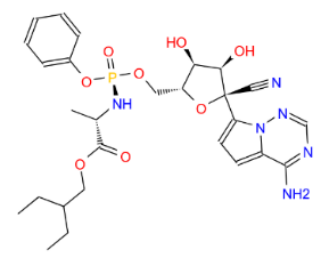

ZINC000166442021

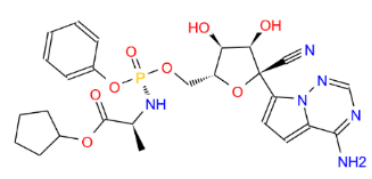

ZINC001772620193

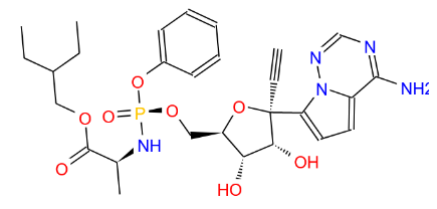

ZINC001772610688

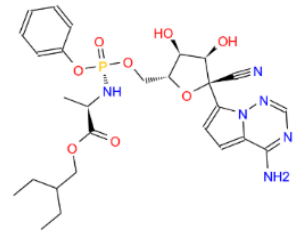

ZINC001772647545

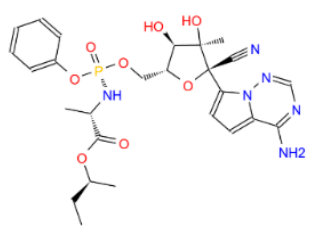

ZINC000103270207

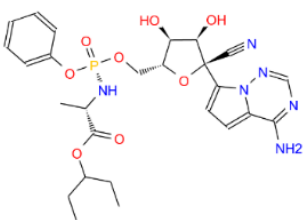

ZINC001772635718

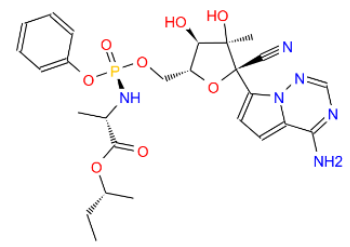

ZINC000103262203

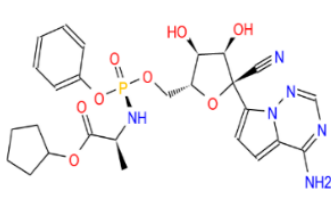

ZINC001772620192

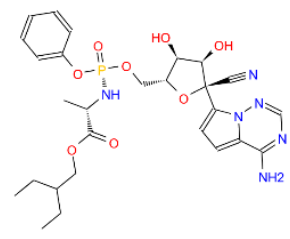

ZINC000166442088 
Aluísio Marques da Fonseca, Antonio Luthierre Gama Cavalcante, Rubson Mateus Matos Carvalho, Jeferson Falcão do Amaral, Regilany Paulo Colares, Emmanuel Silva Marinho, and Moises Maia Neto

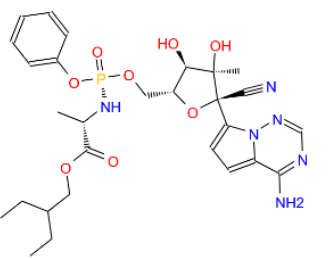

ZINC000103270230

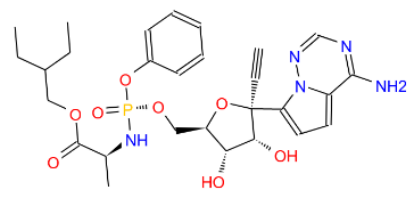

ZINC001772610689

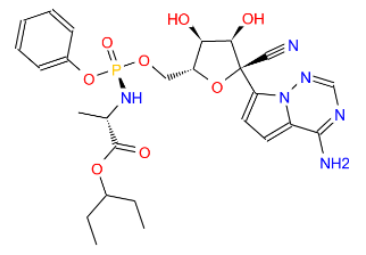

ZINC001772635410

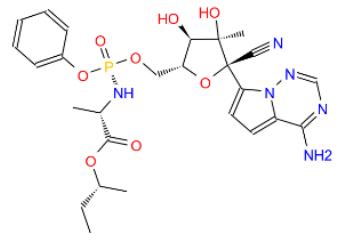

ZINC000103262205

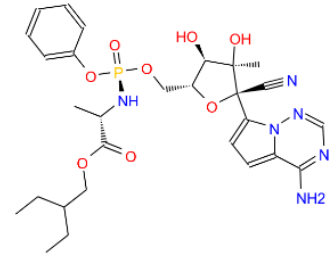

ZINC000103270228

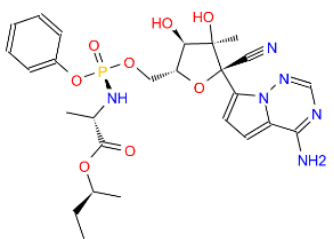

ZINC000103270205

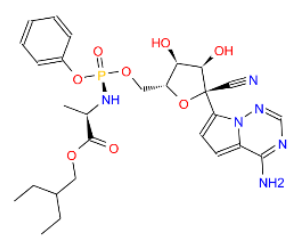

ZINC001772647544

Figure 1: Structure of binders used in the 2D study.

\section{RESULTS AND DISCUSSIONS}

From the molecular docking, it was verified that all 16 ligands and the control (Remdesivir) selected (in yellow) interacted with amino acid residues from the same region of the co-crystallized ligand (N3, in green), as seen in Figure 2.

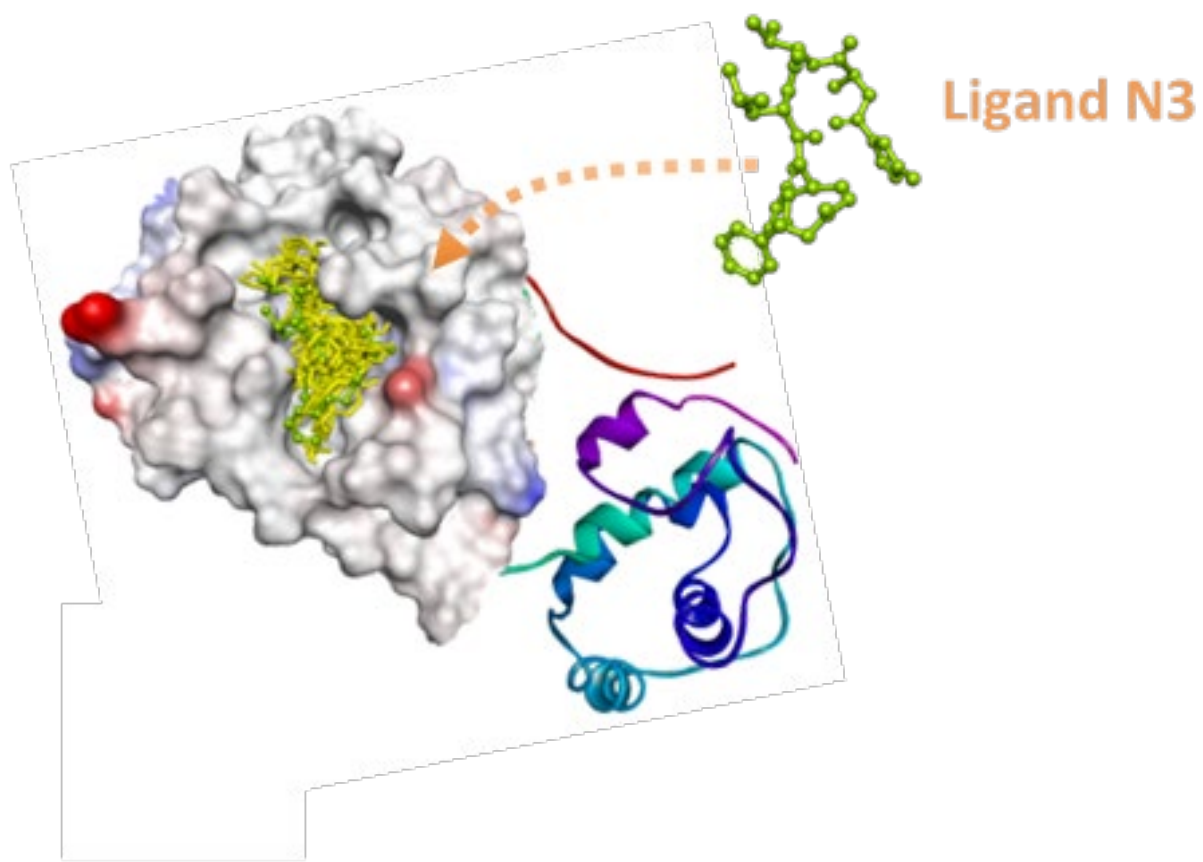

Figure 2: Binders (yellow) anchoring in the same region as the co-crystallized synthetic binder, N3 (green), obtained by Discovery studio. [44]

However, by exclusion, only seven ligands were the most conducive to subsequent analysis based on their affinity energy from the mentioned methodology. They meant standard deviation values of interactions (RMSD), [42] as shown in Figure 3. 


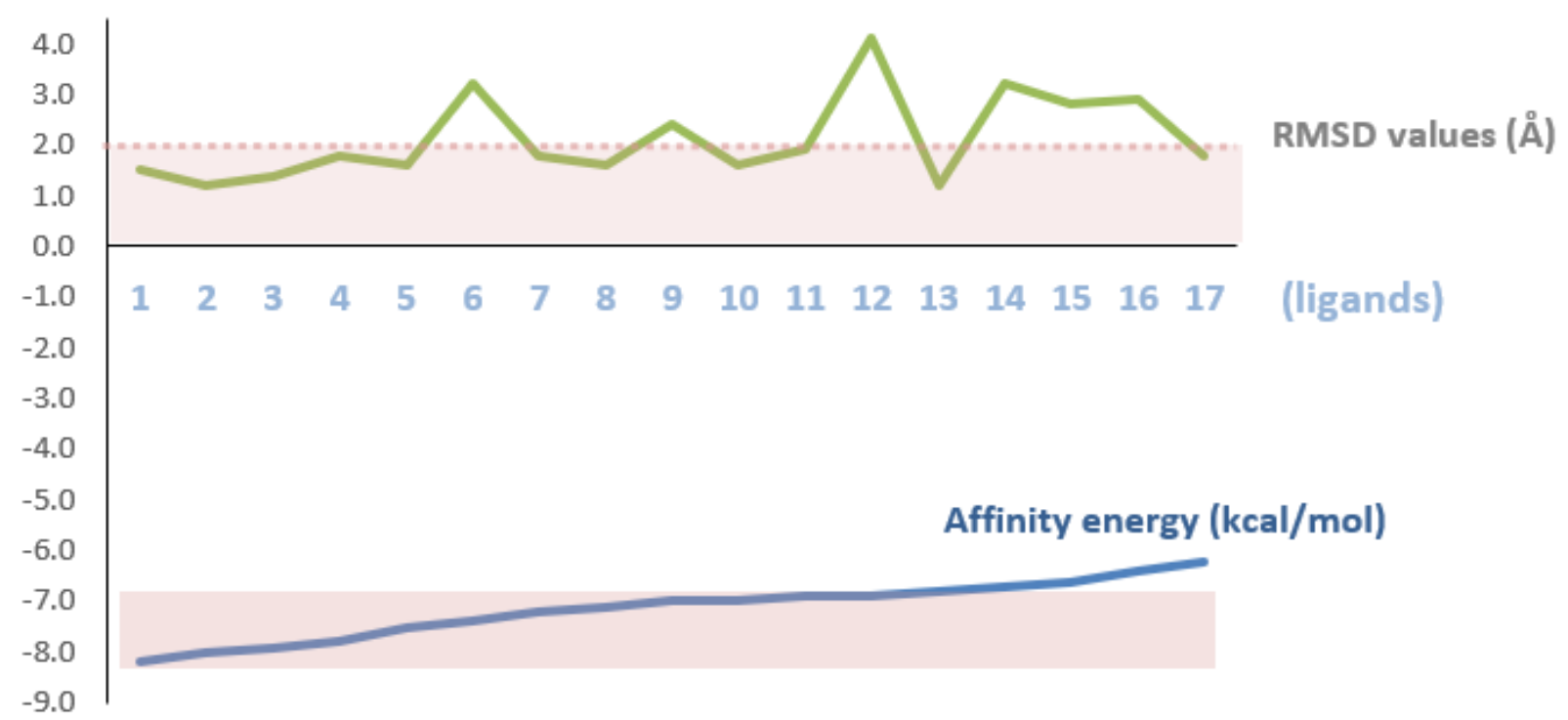

Figure 3: Graph showing the acceptability region of the main ligands.

As seen in Table 1, to facilitate the discussion, it was decided to rename the ligand codes from Zinc15 repository to RemD-1 to RemD-6, as derivatives of Remdesivir (RemD-0). The docking power scale was also presented. Except for RemD-0 (with nine poses), the other ligands gave ten poses, with calculated energy affinity variations from -8.2 to $6.6 \mathrm{kcal} / \mathrm{mol}$. However, the discussion was based on Remd-1 ligands' structure to RemD-6 because they present structures with constitutional alterations and distinct configurations, compared to Remdesivir (RemD-0) and are those with higher and lower energy, respectively.

Table 1: Main binders selected from their structures, affinity energies, RMDS and poses.

\begin{tabular}{|c|c|c|c|}
\hline Docking score (Kcal/mol) & Code ZINC15 & RMDS & Poses \\
\hline$-8.2 \mathrm{a}-7.6$ & ZINC001772620193 (RemD-1) & 1.5 & 10 \\
\hline$-8.0 \mathrm{a}-6.6$ & ZINC001772647545 (RemD-2) & 1.2 & 10 \\
\hline$-7.9 \mathrm{a}-6.9$ & ZINC001772635718 (RemD-3) & 1.4 & 10 \\
\hline$-7.8 \mathrm{a}-6.9$ & REMDESIVIR (RemD-0) & 1.8 & 9 \\
\hline$-7.5 \mathrm{a}-6.9$ & ZINC001772620192 (RemD-4) & 1.6 & 10 \\
\hline$-7.2 \mathrm{a}-6.5$ & ZINC001772610688 (RemD-5) & 1.8 & 10 \\
\hline$-7.1 \mathrm{a}-6.6$ & ZINC000103270207 (RemD-6) & 1.6 & 10 \\
\hline
\end{tabular}

Of these ligands, amino acid residues similar to the protein domain region were analyzed. Each protein protomer was composed of three domains: domain I with residues 8-101, domain II with residues 102-184, in the topology, presented an antiparallel structure of $\beta$-barrel. In domain III, with the residues 201-303, it showed five $\alpha$ helix arranged in a globular cluster largely antiparallel, connected to domain II through an extended loop region with the residues 185-200. [47], [48]

To prove the efficiency of the docking, in the re-docking, it was possible to calculate an average distance variation (VDM) of $0.65 \AA$ (made from the distance of all interaction $(\AA \AA)$ )/number of interaction between the N3 ligand and the protein) in its six residues, which were: Gly143, Hist163, His41, Pro168, Hist172, and Met49, presented in Table 2. In the Remd- 1 antiviral, this calculated variation was lower, of $0.38 \AA$, which justifies its more excellent stability between the formed complex and higher affinity energy $(-8.2 \mathrm{kcal} / \mathrm{mol})$ compared to the cocrystallized ligand, which reached a maximum of $-6.0 \mathrm{kcal} / \mathrm{mol}$. Figure 4 shows the main complexes' two-dimensional diagrams: from the RemD-0 complex to the RemD-6 complex. The targeted connections between the nearest receptor-binding were drawn as dashed lines, and the residues of interactive and binding proteins are visualized as structural diagrams. It is also verified that the hydrophobic contacts were represented more indirectly through sections highlighting the ligand's hydrophobic parts and its contact amino acid. [45], [46] 
A highlight should be given to the derivative RemD-1 $(-8.2 \mathrm{kcal} / \mathrm{mol})$, which presented higher affinity energy about the other binders, having in its structure a tetrahydrofuran ring in the ester part, to the branched and aliphatic chain (2'-ethyl-butyl) of RemD-0, which obtained a gain of approximately 5\% stability in the formation of the complex. The aromatic substructure (aminopyrrole triazil) of RemD-0 is located in the plane of the molecule, forming a hydrogen bond with Thr190, while this same region of RemD-1 is forward, interacting with two residues of the active site, Glu166, and Thr26, which have a polar nature, generating a greater affinity with protease. While in RemD6 , stability is further reduced when the aliphatic chain is with fewer carbons, in the sester sester-butylate part, which decays its affinity energy in the receptor-ligand complex by approximately $9 \%$. This can be justified because introducing a ring of a system changes the conformation and increases the analog's overall size. [49]

Generally, the effect of these changes on the analog's potency and activity is not predictable. [50] However, the increase in length may help fill a hydrophobic/hydrophilic aperture at the target site, strengthening the drug's binding to the target. [51] Remd-2 $(-8.0 \mathrm{kcal} / \mathrm{mol})$ and RemD-3 $(-7.9 \mathrm{kcal} / \mathrm{mol})$ diastereoisomers have a higher binding affinity than RemD-0 $(-7.8 \mathrm{kcal} / \mathrm{mol})$ because they are intrinsically interacting with the protease domain. In addition to better accommodation in the hydrophilic cracks caused by the increase of entropy $(\Delta S)$ of the system from the desolvation (release of water molecules), when two apolar atoms interact, that is, the approximation of hydrophobic surfaces promoting disorganization of the solvation layer favoring interaction, also known as Van der Waals interactions. [52], [53] These hydrophobic interactions play an essential role in the stabilization of receptorligand complexes due to the remarkable hydrophobic characteristics of certain groups or fragments present in bioactive molecules or protein structures. [54]

Compared to RemD-1 (-8.0 kcal $/ \mathrm{mol})$, which has an interaction in protease domains, it generates three hydrogen bonds in the residues: Ser144, Cys145, and His166, which produces greater stability to the formed complex. Also observed are three carbon-hydrogen bonds in the residues: Thr26, Gly143, and Glu166. In the hydrophobic region of the protein, the ligand showed interaction with Met165 (pi-sulfur), Gln189 (unfavorable positive-positive type bond), His41 (Pi-Pi type), and Met49 (Pi-Alkyl type). The diastereoisomer of RemD-1, RemD-4 (-7.6kcal/mol), did not present the same interactions in the simulation because its aromatic region (aminopyrrole triazil) was found in the plane of the molecule, which in some way gave lower energy in the formation of the complex. This behavior is also seen in RemD-5 (-7,2kcal/mol), which has the ester part in the molecule plane, which causes a reduction in its affinity energy, against the RemD-2 $(-8.0 \mathrm{kcal} / \mathrm{mol})$ that is behind. This analysis can be seen in Figure 5.

Table 2: Comparison of distances between residues/ligand.

\begin{tabular}{|c|c|c|c|c|c|c|}
\hline \multirow{3}{*}{$\begin{array}{l}\text { Mpro protease reside } \\
\text { recorded by simulations }\end{array}$} & \multirow{3}{*}{$\begin{array}{c}\text { Protein } \\
\text { domain[48] }\end{array}$} & \multicolumn{5}{|c|}{ Distance from ligand $(\AA)$} \\
\hline & & \multicolumn{3}{|c|}{ Native PDB (average $0.65 \AA$ ) } & \multicolumn{2}{|c|}{$\begin{array}{c}\text { Molecular anchorage result } \\
\text { (average } 0.38 \AA \text { ) }\end{array}$} \\
\hline & & $\begin{array}{l}\text { ligand } \\
\text { N3 }\end{array}$ & $\begin{array}{c}\text { Re- } \\
\text { docking }\end{array}$ & $\begin{array}{c}\text { Difference } \\
\text { between docking }\end{array}$ & $\begin{array}{c}\text { RemD- } \\
1\end{array}$ & $\begin{array}{l}\text { Difference between } \\
\text { docking }\end{array}$ \\
\hline Thr26 & \multirow[t]{3}{*}{ S1 } & & & & $3.3 \AA$ & \\
\hline His41 & & $4.3 \AA$ & $4.5 \AA$ & $0.2 \AA$ & $4.3 \AA$ & $0.0 \AA$ \\
\hline Met49 & & $4.7 \AA$ & $5.5 \AA$ & $0.8 \AA$ & $4.6 \AA$ & $0.1 \AA$ \\
\hline Asn142 & \multirow[t]{9}{*}{$\mathrm{S} 2$} & $4.1 \AA$ & & & & \\
\hline Gly143 & & $2.9 \AA$ & $2.4 \AA$ & $0.5 \AA$ & $3.3 \AA$ & $0.4 \AA$ \\
\hline Ser144 & & & & & $2.6 \AA$ & \\
\hline Cys145 & & & $3.4 \AA$ & & $3.4 \AA$ & $0.0 \AA$ \\
\hline Hist163 & & $2.4 \AA$ & $2.0 \AA$ & $0.4 \AA$ & $2.9 \AA$ & $0.5 \AA$ \\
\hline Met165 & & $4.6 \AA$ & & & $5.7 \AA$ & $1.1 \AA$ \\
\hline Glu166 & & $2.8 \AA$ & & & $3.4 \AA$ & $0.6 \AA$ \\
\hline Pro168 & & $4.9 \AA$ & $5.4 \AA$ & $0.5 \AA$ & & \\
\hline Hist172 & & $3.7 \AA$ & $5.2 \AA$ & $1.5 \AA$ & & \\
\hline Gln189 & S3 & & & & $4.3 \AA$ & \\
\hline
\end{tabular}




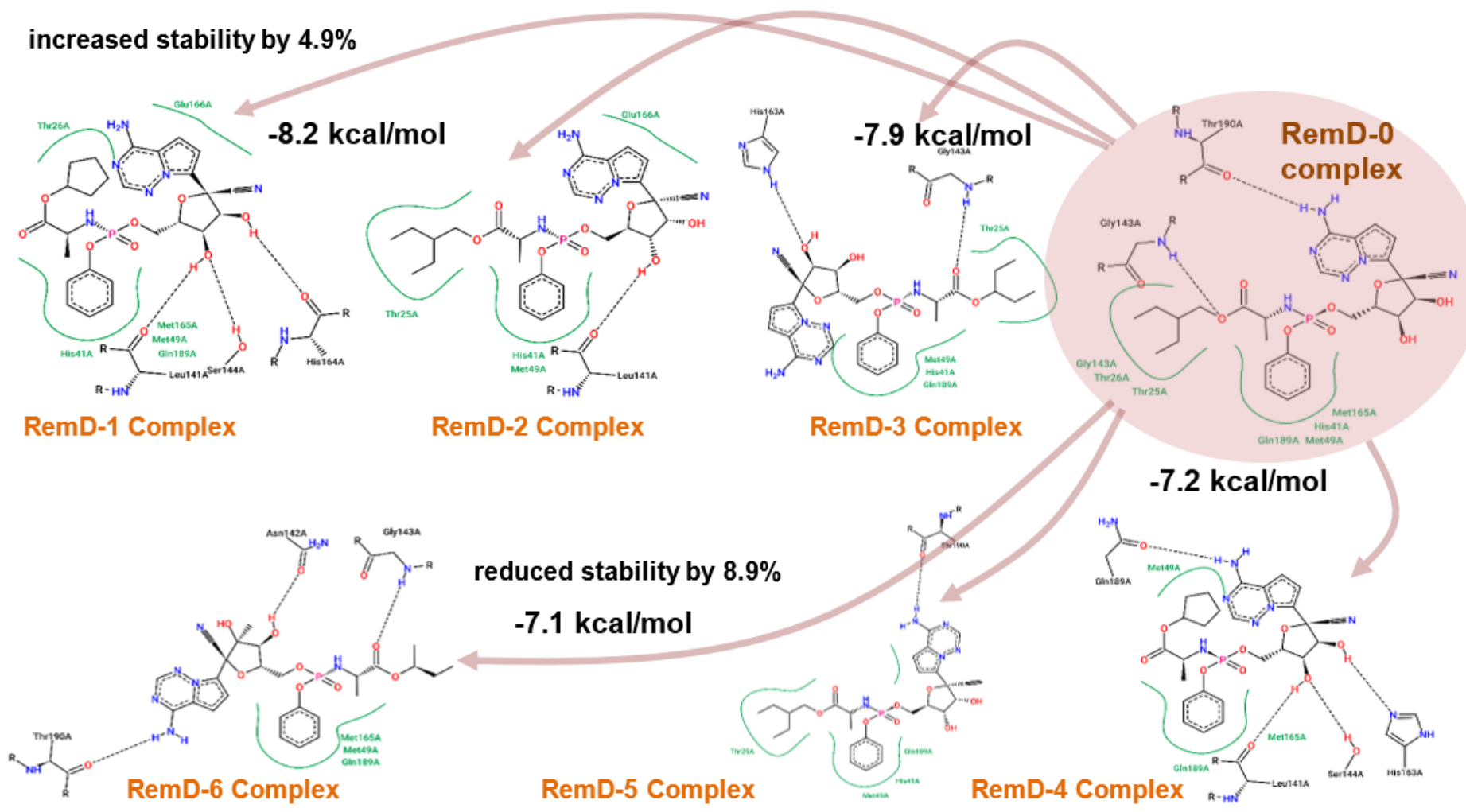

Figure 4: Two-dimensional diagrams of the main complexes analyzed in docking
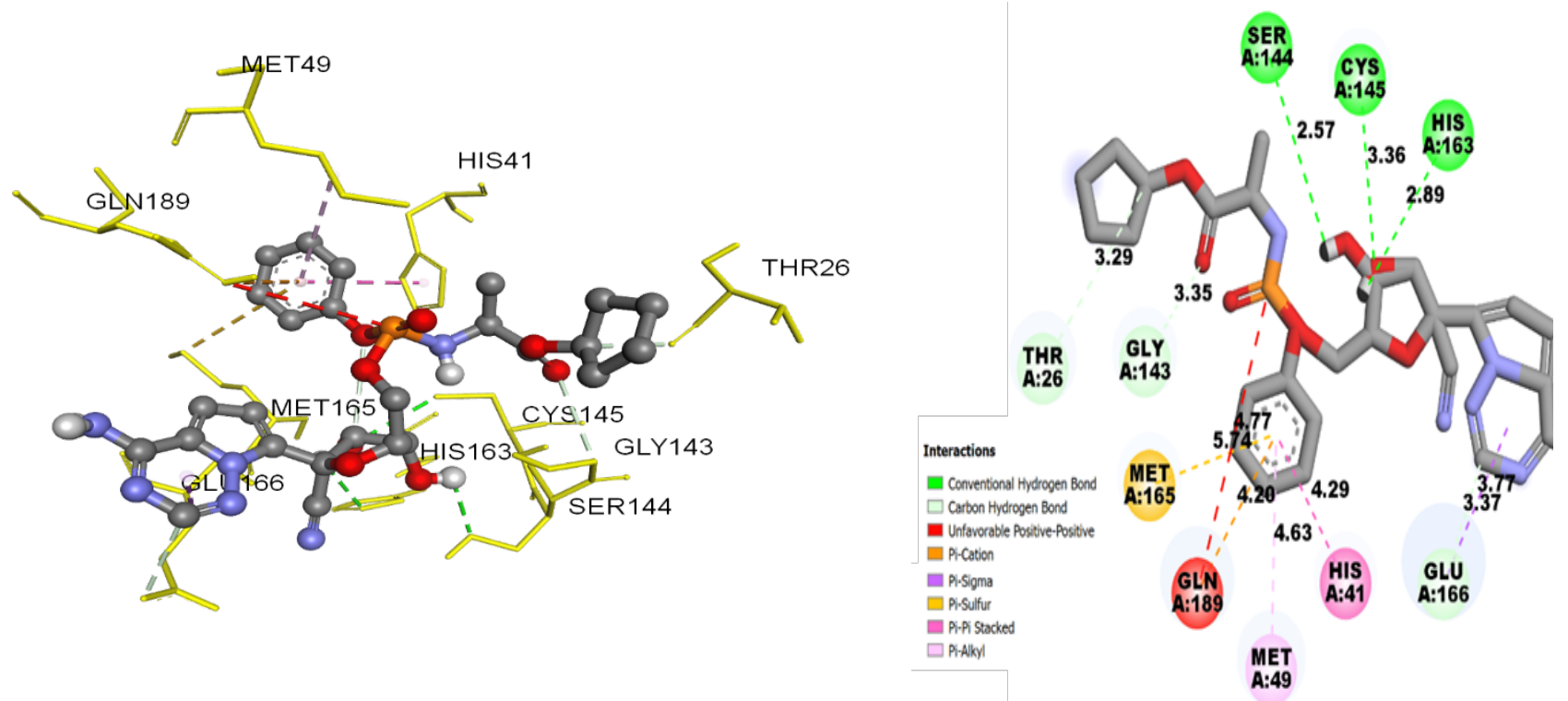

Figure 5: (a) representation of RemD-1 in 3D with the approximation of the residues and their domain (S1-S3) [48]; (b) representation of RemD-1 in 2D with distances $(\AA)$ and type of interaction, performed by discovery studio software. [44]

\section{CONCLUSIONS AND RECOMMENDATIONS}

It was found that both remdesivir and its diastereoisomeric derivatives have an affinity with the main protease (Mpro), responsible for viral replication, with inhibition capacity and possible alternative in its treatment because they present minimal cytotoxic effects, characteristic of promising therapeutic agents and are by Lipinski's protocols. 
Aluísio Marques da Fonseca, Antonio Luthierre Gama Cavalcante, Rubson Mateus Matos Carvalho, Jeferson Falcão do Amaral, Regilany Paulo Colares, Emmanuel Silva Marinho, and Moises Maia Neto

These findings may contribute significantly to future studies and research to support the possible inclusion of remdesivir and its derivatives in new experimental protocols for a drug therapy capable of combating SARS-CoV-2 since COVID-19 causes acute and severe respiratory problems and has led the world population to mass hospitalization and death.

However, it should be clear that the computational assays' data are indicative only and should respect the results of in vitro and in vivo studies, as these are directly related to reactive compounds and biological systems. It is also essential to state that these studies are computational and are often probabilities based on quantum mechanics.

\section{SOURCES OF FUNDING}

This research received no specific grant from any funding agency in the public, commercial, or not-for-profit sectors.

\section{CONFLICT OF INTEREST}

The author have declared that no competing interests exist.

\section{ACKNOWLEDGMENT}

None.

\section{REFERENCES}

[1] C. Leung, Clinical features of deaths in the novel coronavirus epidemic in China, Rev. Med. Virol. (2020). https://doi.org/10.1002/rmv.2103.

[2] M. Jansson, X. Liao, J. Rello, Strengthening ICU health security for a coronavirus epidemic, Intensive Crit. Care Nurs. 57 (2020). https://doi.org/10.1016/j.iccn.2020.102812.

[3] H.A. Rothan, S.N. Byrareddy, The epidemiology and pathogenesis of coronavirus disease (COVID-19) outbreak, J. Autoimmun. 109 (2020) 1-4. https://doi.org/10.1016/j.jaut.2020.102433.

[4] Brasil, COVID19 Painel Coronavírus, Coronavirus - Bras. (2020). https://covid.saude.gov.br/ (accessed March $3,2020)$.

[5] I. Tuñas, E. Silva, S. Santiago, K. Maia, G. Silva-Júnior, Doença pelo Coronavírus 2019 (COVID-19): Uma abordagem preventiva para Odontologia, Rev. Bras. Odontol. 77 (2020) 1-6.

[6] M.A.P. Sáfadi, C. Rodrigues, A.P. Carvalho, A.M. Pimentel, E.N. Berezin, E. Coser, M.A.W. Rocha, S.R. Marques, Novo coronavírus (COVID-19), Dep. Científico Infectol. • Soc. Bras. Pediatr. (2020) 1-12.

[7] D. Benvenuto, M. Giovanetti, A. Ciccozzi, S. Spoto, S. Angeletti, M. Ciccozzi, The 2019-new coronavirus epidemic: Evidence for virus evolution, J. Med. Virol. 92 (2020) 455-459. https://doi.org/10.1002/jmv.25688.

[8] Y. Yang, F. Peng, R. Wang, K. Guan, T. Jiang, G. Xu, J. Sun, C. Chang, The deadly coronaviruses: The 2003 SARS pandemic and the 2020 novel coronavirus epidemic in China, J. Autoimmun. 109 (2020). https://doi.org/10.1016/j.jaut.2020.102434.

[9] J.Y.K. Chan, E.W.Y. Wong, W. Lam, Practical Aspects of Otolaryngologic Clinical Services during the 2019 Novel Coronavirus Epidemic: An Experience in Hong Kong, JAMA Otolaryngol. - Head Neck Surg. 146 (2020) 519520. https://doi.org/10.1001/jamaoto.2020.0488.

[10] F. Kofi Ayittey, C. Dzuvor, M. Kormla Ayittey, N. Bennita Chiwero, A. Habib, Updates on Wuhan 2019 novel coronavirus epidemic, J. Med. Virol. 92 (2020) 403-407. https://doi.org/10.1002/jmv.25695.

[11] C. Ronco, P. Navalesi, J.L. Vincent, Coronavirus epidemic: preparing for extracorporeal organ support in intensive care, Lancet Respir. Med. 8 (2020) 240-241. https://doi.org/10.1016/S2213-2600(20)30060-6.

[12] C. Yang, J. Wang, A mathematical model for the novel coronavirus epidemic in Wuhan, China, Math. Biosci. Eng. 17 (2020) 2708-2724. https://doi.org/10.3934/mbe.2020148. 
Study of The Inhibition Potential of Remdesivir Derivatives on Mpro of Sars-Cov-2

[13] M. Shehata, S. Zhao, P. Gill, Epidemics and primary care in the UK, Fam. Med. Community Heal. 8 (2020) 1-6. https://doi.org/10.1136/fmch-2020-000343.

[14] P.Y. Boëlle, C. Souty, T. Launay, C. Guerrisi, C. Turbelin, S. Behillil, V. Enouf, C. Poletto, B. Lina, S. van der Werf, D. Lévy-Bruhl, V. Colizza, T. Hanslik, T. Blanchon, Excess cases of influenza-like illnesses synchronous with coronavirus disease (COVID-19) epidemic, France, March 2020, 2020. https://doi.org/10.2807/15607917.ES.2020.25.14.2000326.

[15] A. Chevance, D. Gourion, N. Hoertel, P.M. Llorca, P. Thomas, R. Bocher, M.R. Moro, V. Laprévote, A. Benyamina, P. Fossati, M. Masson, E. Leaune, M. Leboyer, R. Gaillard, Ensuring mental health care during the SARS-CoV-2 epidemic in France: A narrative review, Encephale. 46 (2020) 193-201. https://doi.org/10.1016/j.encep.2020.04.005.

[16] P. Magal, G. Webb, Predicting the Number of Reported and Unreported Cases for the COVID-19 Epidemic in South Korea, Italy, France and Germany, SSRN Electron. J. (2020). https://doi.org/10.2139/ssrn.3557360.

[17] J. Ferguson, J.I. Rosser, O. Quintero, J. Scott, A. Subramanian, M. Gumma, A. Rogers, S. Kappagoda, Characteristics and outcomes of coronavirus disease patients under nonsurge conditions, Northern California, USA, March-April 2020, Emerg. Infect. Dis. 26 (2020) 1679-1685. https://doi.org/10.3201/eid2608.201776.

[18] S. Djilali, B. Ghanbari, Coronavirus pandemic: A predictive analysis of the peak outbreak epidemic in South Africa, Turkey, and Brazil, Chaos, Solitons and Fractals. 138 (2020). https://doi.org/10.1016/j.chaos.2020.109971.

[19] R.G.S. Leonel, R. Chammas, G.A. et al. Plonski, University participation in the production of molecular diagnostic tests for the novel coronavirus in Brazil: the response to health challenges, Cad. Saúde Pública. 36 (2020) 26. https://doi.org/https://doi.org/10.1590/0102.

[20] BRASIL, Protocolo de Manejo Clínico da Covid-19 na Atenção Especializada, Ministério da Saúde, 2020.

[21] P.X. Rynkiewicz, G.A. Babbitt, F. Cui, A.O. Hudson, M.L. Lynch, A comparative survey of betacoronavirus strain molecular dynamics identifies key ACE2 binding sites, BioRxiv. (2020). https://doi.org/https://doi.org/10.1101/2020.09.11.293258.

[22] W. Peng, Y. Xu, D. Han, F. Feng, Potential mechanism underlying the effect of matrine on COVID-19 patients revealed through network pharmacological approaches and molecular docking analysis, Arch. Physiol. Biochem. (2020). https://doi.org/10.1080/13813455.2020.1817944.

[23] C. Shivanika, K.S. Deepak, V. Ragunathan, T.S.A. Pawan, D.P. Brindha, Molecular docking, validation, dynamics simulations, and pharmacokinetic prediction of natural compounds against the SARS-CoV-2 main-protease, J. Biomol. Struct. Dyn. (2020) 1-27. https://doi.org/10.1080/07391102.2020.1815584.

[24] R. Majumder, M. Mandal, Screening of plant-based natural compounds as a potential COVID-19 main protease inhibitor: an in silico docking and molecular dynamics simulation approach, J. Biomol. Struct. Dyn. (2020) 116. https://doi.org/10.1080/07391102.2020.1817787.

[25] W. Martin, F. Cheng, Repurposing of FDA-Approved Toremifene to Treat COVID-19 by blocking the spike glycoprotein and NSP14 of SARS-CoV-2, J. Proteome Res. (2020). https://doi.org/10.1021/acs.jproteome.0c00397.

[26] D. Gentile, V. Patamia, A. Scala, M.T. Sciortino, A. Piperno, A. Rescifina, Putative inhibitors of SARS-COV-2 main protease from a library of marine natural products: A virtual screening and molecular modeling study, Mar. Drugs. 18 (2020) 1-19. https://doi.org/10.3390/md18040225.

[27] J. Liang, C. Karagiannis, E. Pitsillou, K.K. Darmawan, K. Ng, A. Hung, T.C. Karagiannis, Site mapping and small molecule blind docking reveal a possible target site on the SARS-CoV-2 main protease dimer interface, Comput. Biol. Chem. 89 (2020). https://doi.org/10.1016/j.compbiolchem.2020.107372.

[28] W.B. Cardoso, S.A. Mendanha, Molecular dynamics simulation of docking structures of SARS-CoV-2 main protease and HIV protease inhibitors, J. Mol. Struct. 1225 (2021). https://doi.org/10.1016/j.molstruc.2020.129143.

[29] J.H. Beigel, K.M. Tomashek, L.E. Dodd, A.K. Mehta, B.S. Zingman, A.C. Kalil, E. Hohmann, H.Y. Chu, A. Luetkemeyer, S. Kline, D. Lopez de Castilla, R.W. Finberg, K. Dierberg, V. Tapson, L. Hsieh, T.F. Patterson, R. Paredes, D.A. Sweeney, W.R. Short, G. Touloumi, D.C. Lye, N. Ohmagari, M. Oh, G.M. Ruiz-Palacios, T. Benfield, G. Fätkenheuer, M.G. Kortepeter, R.L. Atmar, C.B. Creech, J. Lundgren, A.G. Babiker, S. Pett, J.D. Neaton, T.H. Burgess, T. Bonnett, M. Green, M. Makowski, A. Osinusi, S. Nayak, H.C. Lane, Remdesivir for the Treatment of Covid-19 - Preliminary Report, N. Engl. J. Med. 1 (2020) 1-12. https://doi.org/10.1056/nejmoa2007764. 
Aluísio Marques da Fonseca, Antonio Luthierre Gama Cavalcante, Rubson Mateus Matos Carvalho, Jeferson Falcão do Amaral, Regilany Paulo Colares, Emmanuel Silva Marinho, and Moises Maia Neto

[30] M. Wang, R. Cao, L. Zhang, X. Yang, J. Liu, M. Xu, Z. Shi, Z. Hu, W. Zhong, G. Xiao, Remdesivir and chloroquine effectively inhibit the recently emerged novel coronavirus (2019-nCoV) in vitro, Cell Res. 30 (2020) 269-271. https://doi.org/10.1038/s41422-020-0282-0.

[31] S. Serapian, F. Marchetti, A. Triveri, G. Morra, M. Meli, E. Moroni, G.A. Sautto, A. Rasola, G. Colombo, The answer lies in the energy: how simple atomistic molecular dynamics simulations may hold the key to epitope prediction on the fully glycosylated SARS-CoV-2 spike protein, BioRxiv. (2020). https://doi.org/10.1101/2020.07.22.214254.

[32] A. Martorana, C. Gentile, A. Lauria, In Silico Insights into the SARS CoV-2 Main Protease Suggest NADH Endogenous Defences in the Control of the Pandemic Coronavirus Infection, Viruses. 12 (2020) 1-15. https://doi.org/10.3390/v12080805.

[33] P. Rao, A. Shukla, P. Parmar, R.M. Rawal, B. V. Patel, M. Saraf, D. Goswami, Proposing a fungal metaboliteflaviolin as a potential inhibitor of 3CLpro of novel coronavirus SARS-CoV-2 identified using docking and molecular dynamics, J. Biomol. Struct. Dyn. (2020). https://doi.org/10.1080/07391102.2020.1813202.

[34] N. Vergadou, D.N. Theodorou, Molecular modeling investigations of sorption and diffusion of small molecules in Glassy polymers, Membranes (Basel). 9 (2019) 1-35. https://doi.org/10.3390/membranes9080098.

[35] M.K. Awad, M.F. Abdel-Aal, F.M. Atlam, H.A. Hekal, Molecular docking, molecular modeling, vibrational and biological studies of some new heterocyclic $\alpha$-aminophosphonates, Spectrochim. Acta - Part A Mol. Biomol. Spectrosc. 206 (2019) 78-88. https://doi.org/10.1016/j.saa.2018.07.083.

[36] K. Kodchakorn, Y. Poovorawan, K. Suwannakarn, P. Kongtawelert, Molecular modelling investigation for drugs and nutraceuticals against protease of SARS-CoV-2, J. Mol. Graph. Model. 101 (2020). https://doi.org/10.1016/j.jmgm.2020.107717.

[37] T. Sterling, J.J. Irwin, ZINC 15 - Ligand Discovery for Everyone, J. Chem. Inf. Model. 55 (2015) 2324-2337. https://doi.org/10.1021/acs.jcim.5b00559.

[38] G.M. Morris, H. Ruth, W. Lindstrom, M.F. Sanner, R.K. Belew, D.S. Goodsell, A.J. Olson, Software news and updates AutoDock4 and AutoDockTools4: Automated docking with selective receptor flexibility, J. Comput. Chem. 30 (2009) 2785-2791. https://doi.org/10.1002/jcc.21256.

[39] O. Trott, A.J. Olson, AutoDock Vina: Improving the speed and accuracy of docking with a new scoring function, efficient optimization, and multithreading, J. Comput. Chem. 31 (2010) 455-461. https://doi.org/10.1002/jcc.21334.

[40] H.M. Berman, J. Westbrook, Z. Feng, G. Gilliland, T.N. Bhat, H. Weissig, I.N. Shindyalov, P.E. Bourne, The Protein Data Bank, Nucleic Acids Res. (2000). https://doi.org/10.1093/nar/28.1.235.

[41] Benet et al, BDDCS, the Rule of 5 and Drugability, Adv Drug Deliv Rev. (2016) 89-98. https://doi.org/10.1016/j.addr.2016.05.007.

[42] K.E. Hevener, W. Zhao, D.M. Ball, K. Babaoglu, J. Qi, S.W. White, R.E. Lee, Validation of molecular docking programs for virtual screening against dihydropteroate synthase, J. Chem. Inf. Model. 49 (2009) 444-460. https://doi.org/10.1021/ci800293n.

[43] A.B. Gurung, M.A. Ali, A. Bhattacharjee, M. Abul Farah, F. Al-Hemaid, F.M. Abou-Tarboush, K.M. Al-Anazi, F.S.M. Al-Anazi, J. Lee, Molecular docking of the anticancer bioactive compound proceraside with macromolecules involved in the cell cycle and DNA replication, Genet. Mol. Res. 15 (2016) 1-8. https://doi.org/10.4238/gmr.15027829.

[44] Biovia, Dassault Systemes BIOVIA, Discovery Studio Modelling Environment, Release 4.5, Accelrys Softw. Inc. (2015).

[45] K. Stierand, P.C. Maaß, M. Rarey, Molecular complexes at a glance: Automated generation of two-dimensional complex diagrams, Bioinformatics. 22 (2006) 1710-1716. https://doi.org/10.1093/bioinformatics/btl150.

[46] P.C. Fricker, M. Gastreich, M. Rarey, Automated drawing of structural molecular formulas under constraints, J. Chem. Inf. Comput. Sci. 44 (2004) 1065-1078. https://doi.org/10.1021/ci049958u.

[47] Z. Jin, X. Du, Y. Xu, Y. Deng, M. Liu, Y. Zhao, B. Zhang, X. Li, L. Zhang, C. Peng, Y. Duan, J. Yu, L. Wang, K. Yang, F. Liu, R. Jiang, X. Yang, T. You, L. X, Y. X, B. F, L. H, L. X, G. L, X. W, X. G, Q. C, S. Z, J. H, R. Z, Y. H, Structure-based drug design, virtual screening and high-throughput 2 screening rapidly identify antiviral leads targeting COVID-19, BioRxiv. (2020) 1-29. https://doi.org/10.1101/2020.02.26.964882. 
[48] Y. Kumar, H. Singhc, C.N. Patel, In silico prediction of potential inhibitors for the Main protease of SARS-CoV2 using molecular, J. Infect. Public Health. (2020) 1-14. https://doi.org/https://doi.org/10.1016/j.jiph.2020.06.016.

[49] E.J. Barreiro, C.A.M. Fraga, Planejamento racional baseado no mecanismo de ação: Fármacos inteligentes, 2nd ed., Artmed, Rio de Janeiro, 2015.

[50] G. Thomas, Química Medicinal: Uma introdução, 1a ed., Guanabara Koogan S.A., Rio de Janeiro, 2003.

[51] A. Bagatini, C.R. Gomes, M.Z. Masella, G. Rezer, Dexmedetomidina: Farmacologia e uso clínico, Rev. Bras. Anestesiol. 52 (2002) 606-617. https://doi.org/10.1590/S0034-70942002000500012.

[52] S.I. Jeon, J.H. Lee, J.D. Andrade, P.G. De Gennes, Protein-surface interactions in the presence of polyethylene oxide. I. Simplified theory, J. Colloid Interface Sci. 142 (1991) 149-158. https://doi.org/10.1016/00219797(91)90043-8.

[53] D.N. Basov, M.M. Fogler, F.J. García De Abajo, Polaritons in van der Waals materials, Science (80-. ). (2016). https://doi.org/10.1126/science.aag1992.

[54] P.B. Hawk, B.L. Oser, W.H. Summerson, Practical physiological chemistry, 3th ed., Book Company, Nova Iorque, 1954. 